\title{
Dietary macronutrients and fluid intakes in a sample of pregnant women with either gestational diabetes or type 1 diabetes mellitus, assessed in comparison with Polish nutritional guidelines
}

\author{
Aleksandra Kozlowska ${ }^{1}$, Anna Maja Jagielska ${ }^{1}$, Katarzyna Malgorzata Okreglicka ${ }^{1}$, \\ Filip Dabrowski ${ }^{2}$, Krzysztof Kanecki ${ }^{1}$, Aneta Nitsch-Osuch ${ }^{1}$, \\ Mirosław Wielgos², Dorota Bomba-Opon² \\ ${ }^{1}$ Department of Social Medicine and Public Health, Medical University of Warsaw, Poland \\ ${ }^{2} 7^{\text {st }}$ Department of Obstetrics and Gynecology, Medical University of Warsaw, Poland
}

\begin{abstract}
Objectives: Pregnancy is a critical period during which environmental factors such as nutrition can affect development. Maintaining proper nutrition becomes even more significant when pregnant women have diabetes. The aim of this study was to measure changes in energy and macronutrient intakes among pregnant women and patients diagnosed either with gestational diabetes mellitus (GDM) during pregnancy, or, type 1 diabetes mellitus (T1DM) before pregnancy, and to assess the pregnant women's dietary intakes in comparison with Polish Institute of Food and Nutrition nutritional guidelines.

Material and methods: The analysis was conducted among 83 pregnant women (29 GDM patients, 26 T1DM patients and 28 normal pregnancy patients - the control group) from whom we gathered nutritional data during the second part of their pregnancies. Data on each woman's diet during pregnancy was collected is self-completed dietary records during seven consecutive 24-hour periods.

Results: The mean macronutrient intake of the GDM patients was $32.1 \%$ fat, $19.5 \%$ protein, and $48.3 \%$ carbohydrates; in the T1DM group the results were $34.2 \%, 19.4 \%$ and $46.4 \%$ respectively; and in control group they were $31.8 \%, 17.6 \%$ and $50.5 \%$ respectively. This study showed that many of the pregnant women did not reach the recommended level of energy intake during pregnancy. Moreover, most of the women exceeded their fat requirements, and fat intake as a proportion of energy intakes also exceeded the guidelines in more than $60 \%$ of the women across all groups.

Conclusions: The implications and possible causes of excessive fat intake during pregnancy and pregnancies complicated by diabetes are underestimated and undertreated by obstetricians and warrant further investigation, especially in association with gestational weight gain, maternal and fetal perinatal complications, and post-gestational diabetes.
\end{abstract}

Key words: maternal diet, GDM, energy intakes, fluid intakes

Ginekologia Polska 2018; 89, 12: 659-666

\section{INTRODUCTION}

According to the Developmental Origins of Health and Disease (DOHaD) hypothesis, increased susceptibility to disease is partly shaped during fetal programming by links between nutrition, and epigenetic and epigenomic mechanisms. Fetal programming occurs during the critical embryonic and fetal development period in which tissues and organs are created. Insufficient nutrition during this time results in permanent alteration to certain structural and physiological metabolic functions of the fetus [1, 2].

In addition, fetal growth, increases in various maternal tissue and blood volumes, extracellular liquids, amniotic fluid, maternal fat stores, and placental weight are associated with the increase of the mother's dietary requirements. To create a positive energy balance, as recommended by the Polish Institute of Food and Nutrition $(2012,2017)$, 
daily pre-pregnancy energy intakes should be increased by 360 and $475 \mathrm{kcal}$ in the second and third trimesters, respectively. Hence, according Polish standards, pregnant women should increase their protein and fat intake in the second and third trimesters, however there is no specific recommendation for carbohydrates levels during pregnancy [3].

Meeting the basic nutritional requirements of pregnant women diagnosed with gestational diabetes mellitus (GDM) or type 1 diabetes mellitus (T1DM) is very important for appropriate weight gain and maintenance of normoglycemia without ketonuria. Both, GDM and T1DM exert an influence on carbohydrate intolerance resulting in hyperglycaemia and may cause significant health problems for mothers and babies [4-6]. Depending on the population studied and the diagnostic test, studies show that GDM prevalence ranges from between $1 \%$ and $16.4 \%$ while T1DM accounts for 5 -to-10\% of the total cases of diabetes worldwide [6-9]. Although nutritional guidelines for dietary fats and proteins are established for pregnant women and diabetics, there are no specific intake guidelines for dietary fats and proteins for women diagnosed with GDM or pregnant women with type 1 diabetes mellitus (T1DM). However, Polish guidelines for the management of diabetic patients have highlighted that among diabetic pregnant patients 40 to $50 \%$ of the daily calorie intake (minimum $175 \mathrm{~g}$ carbohydrates/day) should come from carbohydrates, and preferably from the low glycemic index carbohydrates [10].

In addition to the roles of the total carbohydrate, protein and fat intakes among pregnant women, studies have also focused on the role of the long chain polyunsaturated fatty acid (LCPUFA). LCPUFA intake in early life is known to influence physiological and metabolic pathways relevant to metabolic "programming" [11]. Reports have shown that the metabolism of LCPUFA is altered in the fetuses of GDM women, suggesting that these changes may also contribute to accelerated fetal growth. Furthermore, abnormal placental transport function in GDM is known to further disturb the materno-fetal transport of LCPUFA which may further result in potential adverse consequences for neurodevelopment and adiposity risks for the offspring [12]. In view of the fact that non communicable diseases in adulthood are influenced by nutritional programming, it is essential for women to maintain optimal levels of LCPUFA during pregnancy, and the balanced ratio of Omega- 6 to Omega- 3 fatty acids in the diet is known to have especially important metabolic implications [13].

Dietary intakes should be examined throughout pregnancy to detect potential imbalances in the macronutrients associated with adverse pregnancy outcomes. However, to date, few studies have assessed diabetic pregnant women's dietary intakes. To our knowledge, no study has assessed the adequacy of diabetic-specific diets in relation to cur- rent nutritional guidelines. Therefore, the purpose of this study was to measure changes in energy and macronutrient intakes between GDM, T1DM and normal pregnancies and to assess pregnant women's dietary intakes in comparison with the current Polish nutritional guidelines.

\section{MATERIAL AND METHODS}

\section{Study population}

Our sample was comprised of 113 pregnant women each with greater than 20 weeks gestational age who were recruited by personnel of the 1 st Department of Obstetrics and Gynaecology and the Department of Social Medicine and Public Health at the Medical University of Warsaw, between September 2016 and March 2018. The subjects' clinical histories were recorded, and each underwent a physical examination. Patients with pre-pregnancy Type 1 diabetes, GDM and normal pregnancy at the time of recruitment were included. However, we excluded those with acute and chronic organ diseases, and those who were younger than 18 years old. Our final sample included 83 pregnant women divided into three groups: the first group (P1) consisted of 29 GDM patients, the second (P2) of 26 T1DM patients, and the third (P3), the control group, consisted of 28 physiological pregnancies. The study recorded nutritional data during the second part of each pregnancy. The study protocol was approved by the Ethical Committee at the Medical University of Warsaw and all subjects gave their written consent to participate in the study.

\section{Dietary Data and Estimated Energy Requirement}

Each woman's total energy intake was assessed based on self-reported seven-day 24-hour dietary records of food consumption and the records were checked by trained investigators during face-to-face interviews. The dietary intake data from women's seven-day 24-h dietary records was converted into energy and nutrient intake data using the dietetic software'Dieta 5' reflecting the Polish Food Composition [14]. The 'Dieta 5' database does not provide information regarding dietary and prenatal supplements. The Estimated Energy Requirements (EERs) and macronutrient requirements were based on and consistent with both the Polish Institute of Food and Nutrition guidelines and the Polish guidelines for the management of diabetic patients $[3,10]$.

\section{Statistical analyses}

The data were collected in a prospective database and analyzed. Within each group of patients, the means and standard deviations for energy and macronutrients, and the percentages for energy from carbohydrates (\% carbohydrates), fat (\% fat) and proteins (\% proteins) were calculated from the seven-day 24-h dietary records. We calculated the proportions of women with dietary values either below or 


\begin{tabular}{|c|c|c|c|c|c|}
\hline Variable & $\begin{array}{l}\text { All }(n=83) \\
\text { Mean } \pm \text { SD }\end{array}$ & $\begin{array}{l}\text { P1 }(n=29) \\
\text { Mean } \pm \text { SD }\end{array}$ & $\begin{array}{l}\text { P2 }(n=26) \\
\text { Mean } \pm \text { SD }\end{array}$ & $\begin{array}{l}\text { P3 }(n=28) \\
\text { Mean } \pm \text { SD }\end{array}$ & p-value \\
\hline Age $[y]$ & $32.1 \pm 4.3$ & $31.5 \pm 4.1$ & $32.6 \pm 5.3$ & $32.2 \pm 3.7$ & 0.62 \\
\hline Gestational age [weeks] & $29.2 \pm 4.0$ & $28.9 \pm 3.7$ & $28.3 \pm 5.8$ & $30.1 \pm 1.5$ & 0.27 \\
\hline Height $[\mathrm{cm}]$ & $166.3 \pm 5.7$ & $165.4 \pm 5.9$ & $168.2 \pm 6.0$ & $165.8 \pm 5.1$ & 0.20 \\
\hline Weight $[\mathrm{kg}]^{* *}$ & $75.0 \pm 15.8$ & $75.9 \pm 19.6$ & $77.7 \pm 18.0$ & $72.0 \pm 7.5$ & 0.41 \\
\hline
\end{tabular}

* $p$-value for measures ANOVA performed to assess variations in the characteristic between groups; group P1 — GDM patients; group P2 - T1DM patients; group P3 - normal pregnancy patients; ** body weight at inclusion in the study; data concerning reliable pre-pregnancy body mass was not available

above both the EERs and the acceptable macronutrient distribution ranges (AMDR). Statistical analyses were performed using SPSS Statistics 20 (IBM, Armonk, NY, USA), Epi Info Version 7.2 (CDC, USA) and Microsoft Excel (Redmond, WA, USA). Finally, an ANOVA test was carried out to assess variations in energy and macronutrient intakes between the three groups of patients.

\section{RESULTS}

Participant characteristics are presented in Table 1. Of the 113 pregnant women recruited, thirty were lost during follow-up, mainly due to their lack of time to devote to the project. Therefore, our results include data from 83 pregnant women with a mean age of $32.1 \pm 4.3$ years and an average gestational age of $29.2 \pm 4.0$ weeks. All of the participants were Caucasian.

\section{Energy, macronutrients, fiber and fluid intake}

Table 2 shows group-specific energy and macronutrient intakes as percentages of the total energy intake derived from the dietary records data in comparison with EERs and AMDRs. No statistically significant difference was observed between the three groups, for energy, protein, carbohydrate, or lipid intakes. However, a significant increase in SFAs and a decrease in PUFAs as percentages of energy intakes were observed between the groups (Tab. 2). The mean, SD, minimum, $25 \%$ ( $1^{\text {st }}$ quartile), median, $75 \%$ ( $3^{\text {rd }}$ quartile) and maximum macronutrients intakes, derived from the 7-d 24-h dietary records, are shown in Table 3. Mean energy intakes were consistent with EERs in all three groups (P1: 1806,5 \pm 529.8; P2: 1694,4 \pm 426.7; and P3: 1883,1 $\pm 335 \mathrm{kcal}$; $\mathrm{p}=0.29$ ). In all groups, protein intakes as a percentage of energy were within the acceptable distribution range (10-30\%). Across all groups, most women reported fat intakes as a percentage of energy intakes above the acceptable distribution range. Moreover, intakes of saturated fatty acids as a percentages of total energy intakes were above the acceptable distribution range for more than $80 \%$ of participants in each group while percentages of polyunsaturated fatty acids as a proportion of energy were below
AMDRs for more than $50 \%$ of all patients. Omega6/Omega 3 ratios were 5.2:1 in the GDM group, 4.3:1 in the T1DM group and 4.4:1 in the control group (Tab. 3). Mean fluid intakes were consistent with AMDRs in all pregnant women. However, fluid intake was below the acceptable distribution range for more than $55 \%$ of patients in the GDM and T1DM groups. Mean dietary fiber intakes were consistent with the acceptable distribution range (20-40 g), although more than $38 \%$ of participants consumed less than the recommended intake (Tab. 4).

\section{DISCUSSION}

An adequate intake of nutrients by pregnant women diagnosed with gestational diabetes mellitus (GDM) or type 1 diabetes (T1DM) is essential to maintain the proper storage of nutrients and development of the fetus within the maternal body. The present study aimed to investigate the energy and macronutrient intake levels of healthy pregnant women, compared with those with GDM orT1DM. Our investigation was important because ensuring proper nutrition during pregnancy without increasing blood glucose levels or causing excessive weight gain is very important for preventing maternal and fetal complications in the population of diabetic patients.

Although it is recommended that pregnant women elevate their caloric intake as their pregnancies progress, and especially during the second and third trimesters, no specific advice has been established regarding the recommended levels of caloric increase for GDM orT1DM pregnant women. We found no differences in the energy intakes between the three groups in our study. Based on the EERs, the caloric intake levels of the GDM group, T1DM group, and control group were 1806, 1694 and $1883 \mathrm{kcal} /$ day, respectively; or, as a percentage of the recommended intake levels for healthy pregnant with similar BMI, 68.6\%, 53.8\% and 39.4\% respectively. In contrast, using a food frequency questionnaire, Lim et al. found that the mean daily caloric intake level of their Korean GDM subjects ( $n=111$ ) was approximately $1596 \mathrm{kcal}$, or $12 \%$ lower than the mean intake level of the GDM subjects in our study [15]. However, it is difficult to 
Table 2. Group-specific energy intakes and macronutrient intakes as a percentage of energy intakes in comparison with the acceptable macronutrient range based on $[3,10,17]$

\begin{tabular}{|c|c|c|c|c|c|c|c|c|c|c|}
\hline & \multicolumn{3}{|c|}{ GDM pregnancy $(n=29)$} & \multicolumn{3}{|c|}{ T1DM pregnancy $(n=26)$} & \multicolumn{4}{|c|}{ Normal pregnancy $(n=28)$} \\
\hline & $\begin{array}{l}\text { Mean } \pm \text { SD } \\
\text { or AMDR } \\
\text { Range }\end{array}$ & $\begin{array}{l}\% \\
\text { Below } \\
\text { AMDR }\end{array}$ & $\begin{array}{l}\% \\
\text { Above } \\
\text { AMDR }\end{array}$ & $\begin{array}{l}\text { Mean } \pm \text { SD } \\
\text { or AMDR }\end{array}$ & $\begin{array}{l}\% \\
\text { Below } \\
\text { AMDR }\end{array}$ & $\begin{array}{l}\% \\
\text { Above } \\
\text { AMDR }\end{array}$ & $\begin{array}{l}\text { Mean } \pm \text { SD or } \\
\text { AMDR }\end{array}$ & $\begin{array}{l}\% \\
\text { Below } \\
\text { AMDR }\end{array}$ & $\begin{array}{l}\% \\
\text { Above } \\
\text { AMDR }\end{array}$ & p-value* \\
\hline EER [kcal/day] & $1500-2400$ & - & - & $1500-2400$ & - & - & $1920-2320$ & - & - & \\
\hline Energy intake [kcal/day] & $1806.5 \pm 529.8$ & 24.4 & 7.0 & $1694.4 \pm 426.7$ & 38.5 & 7.7 & $1883.1 \pm 335.0$ & 53.5 & 7.1 & 0.29 \\
\hline AMDR protein E \% & 30 & - & - & 30 & - & & $10-20$ & - & - & \\
\hline Protein. E\% & $19.5 \pm 3.9$ & 100 & 0 & $19.4 \pm 4.1$ & 100 & 0 & $17.6 \pm 3.1$ & 0 & 14.28 & 0.10 \\
\hline AMDR carbohydrate. E \% & $40-50$ & - & - & $40-50$ & - & - & $45-65$ & - & - & \\
\hline Carbohydrate. E \% & $48.3 \pm 7.6$ & 7.0 & 34.9 & $46.4 \pm 5.1$ & 7.7 & 34.6 & $50.5 \pm 5.2$ & 10.7 & 0 & 0.06 \\
\hline AMDR sugar. E \% & $<10$ & - & - & $<10$ & - & - & $<10$ & - & - & \\
\hline sucrose. E \% & $5.2 \pm 2.1$ & 97.5 & 3.5 & $6.4 \pm 3.1$ & 61.5 & 38.5 & $9.8 \pm 3.0$ & 64.3 & 35.7 & 0.01 \\
\hline AMDR total fat. E \% & $20-30$ & - & - & $20-30$ & - & - & $20-30$ & - & - & \\
\hline Total fat. E \% & $32.1 \pm 6.3$ & 7 & 69.8 & $34.2 \pm 4.3$ & 0 & 80.8 & $31.8 \pm 4.6$ & 0 & 64.3 & 0.2 \\
\hline AMDR SFA. E \% & $<10$ & - & - & $<10$ & - & - & $5-6$ & - & - & \\
\hline SFA. E \% & $12.1 \pm 3.0$ & 13 & 87.0 & $12.3 \pm 2.0$ & 11.5 & 88.5 & $12.1 \pm 1.8$ & 0 & 100 & 0.9 \\
\hline AMDR MUFA. E \% & $10-15$ & - & - & $10-15$ & - & - & $10-15$ & - & - & \\
\hline MUFA. E \% & $13.2 \pm 3.5$ & 20.9 & 27.9 & $14.0 \pm 2.5$ & 3.8 & 26.9 & $13.4 \pm 2.7$ & 10.7 & 25 & 0.56 \\
\hline AMDR PUFA. E \% & $6-10$ & - & - & $6-10$ & - & - & $6-10$ & - & - & \\
\hline PUFA. E \% & $5.0 \pm 1.4$ & 83.8 & 0 & $5.7 \pm 1.3$ & 50 & 0 & $4.7 \pm 1.6$ & 78.5 & 0 & 0.02 \\
\hline AMDR Fluid [mL] & 2300 & - & - & 2300 & - & - & 2300 & - & - & \\
\hline Fluid intake $[\mathrm{mL}]$ & $2439.7 \pm 893.2$ & 55 & 45 & $2315.6 \pm 958.7$ & 69.2 & 30.8 & $2676,78 \pm 803.7$ & 25 & 75 & 0.32 \\
\hline
\end{tabular}

${ }^{*} \mathrm{p}$-value for measures ANOVA performed to assess variations in energy, macronutrient, fluids intakes between groups; AMDR - acceptable macronutrient distribution range based on the Polish Institute of Food and Nutrition Polish nutritional guidelines and Polish guidelines for the management of diabetic patients; EER — estimated energy requirement, consistent with the Polish Institute of Food and Nutrition guidelines and the Polish guidelines for the management of diabetic patients; SFA — saturated fatty acids; MUFA — monounsaturated fatty acids; PUFA — polyunsaturated fatty acids

compare these results, because the Lim study measured caloric intake using a food frequency questionnaire, which is different data collection method than used for our study. In our study we found that almost $24 \%$ of the GDM group, 38\% of T1DM group and $53 \%$ of the control group patients consumed less energy than their EERs. A recent meta-analysis of 18 studies by Jebeile et al. showed little to no change in energy intake across all trimesters during normal pregnancies [16]. Likewise, Savard et al. and Abeysekera et al. found no significant changes in the longitudinal caloric intakes of pregnant women $[17,18]$. Considering these observations, we might question the current caloric guidelines for pregnant women and suggest that the guidelines are set at too high a level, but this hypothesis should be further explored through studies that focus on energy metabolism during pregnancy, and especially in pregnant women diagnosed with GDM or type T1DM.

It is important to achieve the proper management of the carbohydrate intake of pregnant women with GDM and T2DM for postprandial glucose control [7]. A moderately low carbohydrate diet comprising $40-50 \%$ of the woman's total caloric intake has been suggested, however, the recommended minimum daily intake of carbohydrate is $175 \mathrm{~g}$ [3, 10]. The present study found that the women's consumption of carbohydrates was $48.3 \%, 46.4 \%$ and $50.5 \%$ of the total energy intake in the GDM, T1DM and control groups, respectively. In contrast, Liam et al. reported that carbohydrate consumption was $56.6 \%$ of the total energy intake for the GDM patients in their study, which is above the recommended intake level. However, it should be highlighted, that in the present study approximately $25 \%$ of GDM and T1DM patients consumed less than $175 \mathrm{mg}$ of carbohydrates in total. Presumably, the reason why carbohydrate intake was reported to be less than the recommended values was due to the reduced quantity of carbohydrates consumed as a result of doctors' advice or because of the women's concerns about weight control and blood glucose levels after being diagnosed with diabetes or pre-gestational diabetes.

A growing number of experimental animal studies show that exposure to a maternal diet with high levels of added 
Table 3. Group-specific fats and cholesterol intakes

\begin{tabular}{|c|c|c|c|c|c|c|c|c|c|}
\hline & Group & Mean & SD & Min. & $25 \%$ & Median & $75 \%$ & Max. & p-value* \\
\hline \multirow{3}{*}{ Total SFA [g] } & P1 & 24.2 & 9.7 & 10.7 & 18.3 & 21.8 & 26.3 & 62.9 & \multirow{2}{*}{0.66} \\
\hline & P2 & 23.4 & 8.0 & 12.0 & 18.5 & 22.8 & 27.4 & 45.7 & \\
\hline & P3 & 25.4 & 5.8 & 15.1 & 20.9 & 25.9 & 30.1 & 37.5 & \\
\hline \multirow{3}{*}{ Total MUFA [g] } & P1 & 25.9 & 9.3 & 13.8 & 20.9 & 23.6 & 31.5 & 56.8 & \multirow[b]{2}{*}{0.65} \\
\hline & P2 & 26.9 & 10.0 & 12.1 & 20.3 & 25.3 & 32.4 & 54.6 & \\
\hline & P3 & 28.1 & 7.7 & 15.8 & 23.4 & 27.3 & 32.3 & 44.1 & \\
\hline \multirow{2}{*}{ Total PUFA [g] } & P1 & 9.8 & 2.9 & 4.7 & 7.3 & 9.7 & 11.5 & 15.2 & \multirow[b]{2}{*}{0.49} \\
\hline & P2 & 10.8 & 3.8 & 5.4 & 8.5 & 9.7 & 11.9 & 23.0 & \\
\hline \multirow{3}{*}{ EPA $(C 20: 5 n-3)[g]$} & P3 & 9.7 & 3.6 & 4.9 & 7.0 & 8.7 & 12.3 & 19.9 & \\
\hline & P1 & 0.058 & 0.010 & 0 & 0.006 & 0.025 & 0.07 & 0.513 & \multirow[b]{2}{*}{0.36} \\
\hline & P2 & 0.096 & 0.122 & 0 & 0.011 & 0.029 & 0.155 & 0.469 & \\
\hline \multirow{4}{*}{ DHA(C22:6 n-3) [g] } & P3 & 0.057 & 0.103 & 0 & 0.001 & 0.013 & 0.083 & 0.501 & \\
\hline & P1 & 0.170 & 0.258 & 0.008 & 0.041 & 0.0742 & 0.225 & 1.375 & \multirow[b]{2}{*}{0.63} \\
\hline & P2 & 0.223 & 0.273 & 0.004 & 0.064 & 0.0824 & 0.359 & 1.040 & \\
\hline & P3 & 0.155 & 0.290 & 0.010 & 0.024 & 0.0371 & 0.2 & 1.464 & \\
\hline \multirow{2}{*}{ Omega6/Omega3 } & P1 & 5.2 & 2.3 & 1.8 & 3.9 & 4.8 & 5.7 & 13.3 & \multirow[t]{2}{*}{0.11} \\
\hline & P2 & 4.3 & 0.9 & 2.8 & 3.8 & 4.2 & 4.7 & 6.7 & \\
\hline \multirow{4}{*}{ Cholesterol [mg] } & P3 & 4.4 & 1.2 & 1.4 & 4.0 & 4.3 & 4.7 & 7.6 & \multirow{3}{*}{0.14} \\
\hline & P1 & 324.2 & 107.7 & 188.4 & 248.5 & 311.4 & 376.5 & 615.3 & \\
\hline & P2 & 306.2 & 108.5 & 95.3 & 240.9 & 294.9 & 376.0 & 570.6 & \\
\hline & P3 & 273.6 & 66.3 & 154.8 & 227.7 & 273.6 & 312.4 & 416.0 & \\
\hline
\end{tabular}

* $\mathrm{p}$-value for measures ANOVA performed to assess variations in energy and macronutrient intakes between groups; group P1 - GDM patients; group P2 -T1DM patients; group P3 - normal pregnancy patients; SFA — saturated fatty acids; MUFA — monounsaturated fatty acids; PUFA — polyunsaturated fatty acids; EPA — eicosapentaenoic acid; DHA — docosahexaenoic acid

sugar may increase the risk of adult obesity and insulin resistance in offspring. Independent of the total amount consumed, the type of added sugar (sucrose, syrups, etc.) consumed might have a significant impact on the metabolic outcome. A high intake of simple sugars might increase de novo lipogenesis, influence triglyceride production, and decrease fatty acid oxidation $[19,20]$. In our study there was a significant difference in sucrose consumption between the two diabetic groups and the control group, namely, the sucrose intakes were $5.2 \%, 6.4 \%$ and $98 \%$ of the total energy intake for the GDM, T1DM and control groups, respectively.

In parallel with the energy insufficiency observed in pregnant patients, we found that in all groups, more than $60 \%$ of our study sample reported fat intakes exceeding the acceptable range when considered as a percentage of total energy intake. These results are similar to those of Dubois et al. in which a third of the 1533 pregnant Canadian women studied had total fat intakes above the recommended range [21]. Moreover, Savard et al. found that more than half of their study sample reported higher fat intakes than the acceptable range [17]. We recommend that pregnant women with GDM or T1DM should be advised to reduce their carbohydrate intake and increase their protein and fat intake, and that women with pre-gestational diabetes should be provided with dietary education that emphasizes glucose control during the early stage of pregnancy.

WHO recommends that SFA intake should represent less than $10 \%$ of the energy intake in the general adult population, with no other specifications made for women with, or at risk of, GDM [22]. Although SFA consumption, especially long-chain SFA, was associated with higher risk of cardiovascular disease and T2D, its role on cardiometabolic health remains controversial [23, 24]. Alarmingly, in our own study, more than $80 \%$ of the participants consumed SFA at levels comprising more than $10 \%$ of their total energy intake. Furthermore, the balanced ratio of Omega- 6 to Omega-3 fatty acids in the diet was 5.2:1, 4.3:1 and 4.4:1 in the GDM, T1DM and control groups, respectively. Wadhawni et al. highlighted that, for the prevention and management of chronic diseases, it becomes important to reduce the intake of Omega- 6 fatty acids and increase the intake of Omega-3 fatty acids. Furthermore, an optimal Omega- $6 \mathrm{~m}$ to Omega-3 ratio is also recommended during various phases of life, and that includes pregnancy. However, the dietary shifts over the years towards a Western diet has caused a drastic change in the ratio of Omega- 6 to Omega-3 fatty ac- 
Table 4. Group-specific energy intakes and macronutrient intakes in kcal or $\mathrm{g}$

\begin{tabular}{|c|c|c|c|c|c|c|c|c|c|}
\hline & Group & Mean & SD & Min. & $25 \%$ & Median & $75 \%$ & Max. & p-value* \\
\hline \multirow{3}{*}{$\begin{array}{l}\text { Total Energy Intake } \\
\text { [kcal] }\end{array}$} & P1 & 1806.5 & 529.8 & 1084.7 & 1568.5 & 1788.5 & 1974.1 & 3358.6 & \multirow{3}{*}{0.29} \\
\hline & P2 & 1694.4 & 426.7 & 1034.9 & 1428.3 & 1691.8 & 1957.8 & 2731.8 & \\
\hline & P3 & 1883.1 & 335.0 & 1172.1 & 1629.4 & 1887.8 & 2118.2 & 2615.0 & \\
\hline \multirow{3}{*}{ Fluid [mL] } & P1 & 2439.7 & 893.2 & 1256.7 & 1755.0 & 2237.0 & 3439.3 & 4060.5 & \multirow{3}{*}{0.32} \\
\hline & P2 & 2315.6 & 958.6 & 992.9 & 1663.7 & 2010.0 & 3031.5 & 5420.4 & \\
\hline & P3 & 2676.8 & 803.7 & 1151.8 & 2271.8 & 2673.8 & 3267.5 & 4241.1 & \\
\hline \multirow{3}{*}{ Total protein [g] } & P1 & 84.3 & 18.9 & 55.4 & 69.1 & 81.4 & 97.6 & 130.4 & \multirow{3}{*}{0.79} \\
\hline & P2 & 80.6 & 20.4 & 34.4 & 65.9 & 81.4 & 95.9 & 112.6 & \\
\hline & P3 & 82.1 & 20.4 & 46.3 & 68.5 & 80.3 & 91.5 & 132.6 & \\
\hline \multirow{3}{*}{ Animal protein [g] } & P1 & 57.0 & 14.0 & 32.7 & 45.8 & 53.0 & 65.9 & 87.3 & \multirow{3}{*}{0.88} \\
\hline & P2 & 56.2 & 18.1 & 19.1 & 41.1 & 55.5 & 70.1 & 88.6 & \\
\hline & P3 & 54.8 & 17.6 & 22.3 & 46.0 & 51.9 & 58.9 & 102.5 & \\
\hline \multirow{3}{*}{$\begin{array}{l}\text { Non-animal protein } \\
\text { [g] }\end{array}$} & P1 & 26.4 & 8.0 & 12.0 & 21.1 & 26.2 & 29.7 & 49.9 & \multirow{3}{*}{0.27} \\
\hline & P2 & 23.6 & 6.9 & 14.5 & 19.0 & 23.5 & 26.5 & 42.9 & \\
\hline & P3 & 26.2 & 6.8 & 14.7 & 22.2 & 24.6 & 31.1 & 40.3 & \\
\hline \multirow{3}{*}{ Fats [g] } & P1 & 65.1 & 20.8 & 33.0 & 50.0 & 62.2 & 75.1 & 144.6 & \multirow{3}{*}{0.79} \\
\hline & P2 & 66.3 & 21.4 & 34.7 & 52.0 & 65.5 & 77.3 & 114.1 & \\
\hline & P3 & 68.6 & 15.6 & 39.6 & 58.1 & 68.3 & 78.8 & 103.0 & \\
\hline \multirow{3}{*}{ Carbohydrates [g] } & P1 & 244.5 & 108.2 & 126.5 & 174.4 & 230.6 & 268.2 & 680.1 & \multirow{3}{*}{0.16} \\
\hline & P2 & 214.7 & 55.5 & 123.5 & 169.8 & 214.0 & 247.0 & 363.9 & \\
\hline & P3 & 253.3 & 50.3 & 146.0 & 220.2 & 261.0 & 287.0 & 357.0 & \\
\hline \multirow{3}{*}{ Sucrose $[\mathrm{g}]$} & P1 & 23.5 & 12.2 & 10.4 & 13.9 & 20.0 & 26.8 & 56.4 & \multirow{3}{*}{0.01} \\
\hline & P2 & 27.3 & 14.9 & 11.2 & 15.3 & 21.6 & 35.8 & 65.8 & \\
\hline & P3 & 45.9 & 15.0 & 15.7 & 35.1 & 47.8 & 53.5 & 83.7 & \\
\hline \multirow{3}{*}{ Fiber [g] } & P1 & 25.2 & 10.0 & 12.7 & 18.2 & 24.9 & 28.5 & 63.6 & \multirow{3}{*}{0.12} \\
\hline & P2 & 22.3 & 6.1 & 10.7 & 18.6 & 21.7 & 26.9 & 34.4 & \\
\hline & P3 & 21.1 & 5.8 & 12.7 & 15.7 & 21.0 & 25.0 & 33.7 & \\
\hline
\end{tabular}

${ }^{*} \mathrm{p}$-value for measures ANOVA performed to assess variations in energy and macronutrient intakes between groups; group P1 — GDM patients; group P2 — T1DM patients; group P3 - normal pregnancy patients

ids from 1:1 to 20-30:1 [25]. This transition in the Omega- 6 to Omega-3 fatty acid ratio may influence placental development and promote the pathogenesis of several chronic diseases $[13,26]$. Many international scientific societies, including the Polish Gynaecological Society, recommend the use of $600 \mathrm{mg}$ of DHA daily for the prevention of premature labor [27]. In our study more than $75 \%$ of all patients consumed less DHA than the amount recommended. Assessments of dietary intakes in various populations suggest that pregnant women have difficulty meeting all their DHA requirements through diet alone [13]. Harton et al. showed in their study involving 30 Polish women during the third trimester of pregnancy, that less DHA was used than recommended [28].

The role of low and high protein maternal diets in the health outcomes of offspring has been extensively examined in animals especially $[29,30]$. Both low and high protein diets during pregnancy influence body weight, blood pressure, and metabolic and intake regulatory systems in the offspring [29]. Studies show that high protein maternal diets may have an influence on the development of glucose intolerance and diabetes in offspring [30]. Collaterally with the fat excess observed in all the groups of pregnant women we studied, we found that, in each group, all the participants consumed an adequate intake of protein. However, protein from animal sources outbalance plant protein. It should be noted that a higher consumption of animal protein may increase fat intake, especially intake of SFA [3].

Water is one of the six basic nutrients essential to health, especially for pregnant women. Hydration during pregnancy seems to play a crucial role in organism homeostasis. Amniotic fluid is crucial to maintaining fetal wellbeing. Therefore, an amniotic fluid deficiency can cause conditions such as oligohydramnios, which influences the prognosis of a pregnancy. In women with normal amniotic fluid, ma- 
ternal oral hydration increases the amniotic fluid index by approximately $16 \%$, whereas fluid restriction decreases the amniotic fluid index by approximately $8 \%$ [31]. In our study mean fluid intakes were consistent with AMDRs in all the pregnant women. However, fluid intake was below the acceptable distribution range for more than $55 \%$ of patients in the GDM and T1DM groups and for $25 \%$ of the patients in the control group. Similarly, in a study of 300 pregnant women in Indonesia, $42 \%$ of the subjects did not reach an adequate intake of water [32]. There is evidence of potentially positive health benefits resulting from an increased water intake during normal pregnancies and pregnancies complicated with diabetes. It seems that midwives, gynecologists and other doctors should promote an increased water intake, especially among pregnant women with diabetes.

Our study has certain limitations. The most substantial limitation of this study was the small size, and the lack of representativeness of our study sample, however all the pregnant women enrolled were Caucasians and at the similar age. Another limitation was the observational design that did not permit the establishment of causality. However, to the best of our knowledge, no other research has focused on the dietary intakes of pregnant Polish women and patients diagnosed with GDM during pregnancy or pre-gestational T1DM. One of the evident strongpoints of our study is the fact that it is the first study to prospectively assess whether the diets of pregnant women and pregnant women with diabetes meet current Polish nutritional guidelines. Furthermore, this study helps to remedy the lack of available information in Poland regarding macronutrients and fluid intakes by pregnant women. In this regard, the results we obtained are original as well as clinically and epidemiologically important.

\section{CONCLUSIONS}

In summary, the results of the present study indicate that, contrary to current guidelines, there was a stability in dietary intakes among pregnant women and patients diagnosed with GDM during pregnancy or pre-gestational T1DM. However, most women exceeded their fat requirements. Interestingly, the level of DHA intakes from food alone remains low in the diets of our pregnant women. The implications and possible causes of excessive total fat and insufficient DHA intakes in pregnancy and in pregnancies complicated with diabetes are not well documented and should be further investigated in association with gestational weight gain and other metabolic outcomes. Based on our results, it is strongly recommended that this population be provided with appropriate nutritional education before and during pregnancy to prevent maternal and fetal perinatal complications and post-gestational diabetes, obesity, and cardiovascular diseases.

\section{REFERENCES}

1. Guéant JL, Namour F, Guéant-Rodriguez RM, et al. Folate and fetal programming: a play in epigenomics? Trends Endocrinol Metab. 2013; 24(6): 279-289, doi: 10.1016/j.tem.2013.01.010, indexed in Pubmed: 23474063.

2. Kwon E, Kim Y. What is fetal programming?: a lifetime health is under the control of in utero health. Obstetrics \& Gynecology Science. 2017; 60(6): 506, doi: 10.5468/ogs.2017.60.6.506.

3. Jarosz M. Nutritional norms for the Polish population. 2nd ed PloFa. ;2017.

4. Damm P, Houshmand-Oeregaard A, Kelstrup L, et al. Gestational diabetes mellitus and long-term consequences for mother and offspring: a view from Denmark. Diabetologia. 2016; 59(7): 1396-1399, doi: 10.1007/s00125-016-3985-5.

5. Ruchat SM, Mottola M. The important role of physical activity in the prevention and management of gestational diabetes mellitus. Diabetes/Metabolism Research and Reviews. 2013; 29(5): 334-346, doi: 10.1002/dmrr.2402.

6. Colagiuri S, Falavigna M, Agarwal M, et al. Strategies for implementing the WHO diagnostic criteria and classification of hyperglycaemia first detected in pregnancy. Diabetes Research and Clinical Practice. 2014; 103(3): 364-372, doi: 10.1016/j.diabres.2014.02.012.

7. Cho N. Gestational diabetes mellitus-Challenges in research and management. Diabetes Research and Clinical Practice. 2013; 99(2): 237-239, doi: 10.1016/j.diabres.2013.02.007.

8. Maahs D, West N, Lawrence J, et al. Epidemiology of Type 1 Diabetes. Endocrinology and Metabolism Clinics of North America. 2010; 39(3): 481-497, doi: 10.1016/j.ecl.2010.05.011.

9. Mack L, Tomich P. Gestational Diabetes. Obstetrics and Gynecology Clinics of North America. 2017; 44(2): 207-217, doi: 10.1016/j. ogc.2017.02.002.

10. Gumprecht J. Guidelines on the management of diabetic patients. Recommendation of Polish Daibetes Society. Via Medica. ; 2017(3): 1-92.

11. Mennitti LV, Oliveira JL, Morais CA, et al. Type of fatty acids in maternal diets during pregnancy and/or lactation and metabolic consequences of the offspring. J Nutr Biochem. 2015; 26(2): 99-111, doi: 10.1016/j. jnutbio.2014.10.001, indexed in Pubmed: 25459884.

12. Ortega-Senovilla H, Alvino G, Taricco E, et al. Gestational Diabetes Mellitus Upsets the Proportion of Fatty Acids in Umbilical Arterial but Not Venous Plasma. Diabetes Care. 2008; 32(1): 120-122, doi: 10.2337/dc08-0679.

13. Wadhwani N, Patil V, Joshi S. Maternal long chain polyunsaturated fatty acid status and pregnancy complications. Prostaglandins, Leukotrienes and Essential Fatty Acids. 2018; 136: 143-152, doi: 10.1016/j. plefa.2017.08.002.

14. Kunachowicz H, Przygoda B, Iwanow K. Tabele składu i wartosci odzywczej zywnosci. Wydawnictwo Lekarskie PZWL, Warszawa. 2005.

15. Lim SY, Yoo HJ, Kim AL, et al. Nutritional intake of pregnant women with gestational diabetes or type 2 diabetes mellitus. Clin Nutr Res. 2013; 2(2): 81-90, doi: 10.7762/cnr.2013.2.2.81, indexed in Pubmed: 23908974.

16. Jebeile $\mathrm{H}$, Mijatovic J, Louie J, et al. A systematic review and metaanalysis of energy intake and weight gain in pregnancy. American Journal of Obstetrics and Gynecology. 2016; 214(4): 465-483, doi: 10.1016/j. ajog.2015.12.049.

17. Savard C, Lemieux S, Weisnagel S, et al. Trimester-Specific Dietary Intakes in a Sample of French-Canadian Pregnant Women in Comparison with National Nutritional Guidelines. Nutrients. 2018; 10(6): 768, doi: 10.3390/nu10060768.

18. Abeysekera M, Morris J, Davis G, et al. Alterations in energy homeostasis to favour adipose tissue gain: A longitudinal study in healthy pregnant women. Australian and New Zealand Journal of Obstetrics and Gynaecology. 2015; 56(1): 42-48, doi: 10.1111/ajo.12398.

19. Yuruk AA, Nergiz-Unal R. Maternal dietary free or bound fructose diversely influence developmental programming of lipogenesis. Lipids Health Dis. 2017; 16(1): 226, doi: 10.1186/s12944-017-0618-z, indexed in Pubmed: 29191195.

20. Saad A, Dickerson J, Kechichian T, et al. High-fructose diet in pregnancy leads to fetal programming of hypertension, insulin resistance, and obesity in adult offspring. American Journal of Obstetrics and Gynecology. 2016; 215(3): 378.e1-378.e6, doi: 10.1016/j.ajog.2016.03.038.

21. Dubois $L$, Diasparra $M$, Bédard $B$, et al. Adequacy of nutritional intake from food and supplements in a cohort of pregnant women in Québec, Canada: the 3D Cohort Study (Design, Develop, Discover). The American Journal of Clinical Nutrition. 2017; 106(2): 541-548, doi: 10.3945/ajcn.117.155499. 
22. Dietary fats and oils in human nutrition. Report of an Expert Consultation jointly organized by the Food and Agriculture Organization of the United Nations and the World Health Organization held in Rome, 21-30 September 1977. FAO Food Nutr Ser. 1980; 91 (20): i-xv, 1, indexed in Pubmed: 7002586.

23. Taschereau-Charron A, Da Silva MS, Bilodeau JF, et al. Alterations of fatty acid profiles in gestational diabetes and influence of the diet. Maturitas. 2017;99: 98-104, doi: 10.1016/j.maturitas.2017.01.014, indexed in Pubmed: 28364876.

24. Dyson PA. Saturated fat and Type 2 diabetes: where do we stand? Diabet Med. 2016; 33(10): 1312-1314, doi: 10.1111/dme.13176, indexed in Pubmed: 27352943.

25. Gómez Candela C, Bermejo López LM, Loria Kohen V. Importance of a balanced omega 6/omega 3 ratio for the maintenance of health: nutritional recommendations. Nutr Hosp. 2011; 26(2): 323-329, doi: 10.1590/S0212-16112011000200013, indexed in Pubmed: 21666970.

26. Meher A, Joshi A, Joshi S. Maternal micronutrients, omega-3 fatty acids, and placental PPARy expression. Applied Physiology, Nutrition, and Metabolism. 2014; 39(7): 793-800, doi: 10.1139/apnm-2013-0518.

27. Polish Gynecological Society, Polish Gynecological Society. Recommendations of the Polish Gynecological Society concerning docosahexae- noic acid supplementation in the prevention of preterm birth. Ginekol Pol. 2014; 85(4): 318-320, indexed in Pubmed: 24834713.

28. Harton A, Choroszewska A, Gajewska D, et al. Spożycie wielonienasyconych kwasów tłuszczowych przez kobiety ciężarne. Probl Hig i Epidemiol. 2013; 94: 605-609.

29. Jahan-Mihan A, Rodriguez J, Christie $C$, et al. The Role of Materna Dietary Proteins in Development of Metabolic Syndrome in Offspring. Nutrients. 2015; 7(11): 9185-9217, doi: 10.3390/nu7115460.

30. Metges C, Görs S, Lang l, et al. Low and High Dietary Protein:Carbohydrate Ratios during Pregnancy Affect Materno-Fetal Glucose Metabolism in Pigs. The Journal of Nutrition. 2013; 144(2): 155-163, doi: 10.3945/jn.113.182691.

31. Mulyani EY, Briawan D, Santoso BI. Hydration status of pregnant women in West Jakarta. Asia Pac J Clin Nutr. 2017; 26(Suppl 1): S26-S30, doi: 10.6133/apjcn.062017.s14, indexed in Pubmed: 28625033.

32. Bardosono S, Prasmusinto D, Hadiati $D$, et al. Fluid Intake of Pregnant and Breastfeeding Women in Indonesia: A Cross-Sectional Survey with a Seven-Day Fluid Specific Record. Nutrients. 2016; 8(11): 651, doi: 10.3390/nu8110651. 